\title{
Getting the phenotypes right: an essential ingredient for understanding aetiological mechanisms underlying persistent violence and developing effective treatments
}

\author{
Sheilagh Hodgins ${ }^{1 *}$, Stephane de Brito ${ }^{1,2}$, Emily Simonoff ${ }^{3}$, Timo Vloet ${ }^{4}$ and Essi Viding ${ }^{2}$ \\ Department of Forensic Mental Health Science, Institute of Psychiatry, King's College London, London, UK \\ 2 Developmental Risk and Resilience Unit, Research Department of Clinical Educational and Health Psychology, Division of Psychology and Language Sciences, \\ University College London, London, UK \\ ${ }_{3}$ Department of Child and Adolescent Psychiatry, Institute of Psychiatry, King's College London, London, UK \\ ${ }^{4}$ Department of Child and Adolescent Psychiatry, Medical Faculty, RWTHAachen University, Aachen, Germany
}

\section{Edited by:}

Guillaume Poirier, Ecole Polytechnique

Fédérale de Lausanne, Switzerland

\section{Reviewed by:}

Philipp Sterzer, University Hospital

Charité, Germany

Andreas Meyer-Lindenberg, Central

Institute of Mental Health, Germany

\section{*Correspondence:}

Sheilagh Hodgins, Department of Forensic Mental Health Science, Box PO23, Institute of Psychiatry, King's College London, De Crespigny Park, Denmark Hill, London SE5 8AF, UK. e-mail: sheilagh.hodgins@kcl.ac.uk
In order to reduce societal levels of violence, it is essential to advance understanding of the neurobiological mechanisms involved in initiating and maintaining individual patterns of physical aggression. New technologies such as Magnetic Resonance Imagining and analyses of DNA provide tools for identifying these mechanisms. The reliability and validity of the results of studies using these tools depend not only on aspects of the technology, but also on the methodological rigour with which the studies are conducted, particularly with respect to characterizing the phenotype. The present article discusses five challenges confronting scientists who aim to advance understanding of the neurobiological mechanisms associated with persistent violence. These challenges are: (1) to develop evidence-based hypotheses and to design studies that test alternate hypotheses; (2) to recruit samples that are homogeneous with respect to variables that may be linked to neurobiological mechanisms underpinning violent behaviour; (3) to use reliable and valid measures in order to fully characterize participants so that the external validity of the results is evident; (4) to restrict the range of age of participants so as not to confuse developmental change with group differences; and (5) to take account of sex. Our goal is to contribute to elevating methodological standards in this new field of research and to thereby improve the validity of results and move closer to finding effective ways to reduce violence.

Keywords: phenotypes, persistent violence, etiology, treatment
Getting the phenotypes right: An essential ingredient for understanding aetiological mechanisms underlying persistent violence

"If neuroscience is to shed light on psychopathology, it is imperative that we improve our phenotyping instruments. As behavioral neuroscientists have known for many years, the success in elucidating the neural underpinning of a given behaviour depends to a great degree on how carefully and specifically the behaviour is described."

(Nelson and Jeste, 2008, p. 157)

\section{INTRODUCTION}

In order to reduce societal levels of violence, it is essential to advance understanding of the neurobiological mechanisms involved in initiating and maintaining individual patterns of physical aggression. New technologies such as Magnetic Resonance Imagining and analyses of DNA provide tools for identifying these mechanisms. The reliability and validity of the results of studies using these tools depend not only on aspects of the technology, but also on the methodological rigour with which the studies are conducted, particularly with respect to characterizing the phenotype. The present article discusses five challenges that need to be addressed in an effort to increase the robustness of findings. Our goal is to contribute to elevating methodological standards in this new field of research and to thereby improve the validity of results and move closer to finding effective ways to reduce violence.

\section{PERSISTENT VIOLENT OFFENDERS}

Prospective, longitudinal investigations have shown that approximately $5 \%$ of males and less than $1 \%$ of females display a pattern of physically aggressive behaviour towards others that emerges in childhood and remains stable at least through the first three to four decades of adult life (Farrington and West, 1993; Kratzer and Hodgins, 1999; Moffitt et al., 2002). The aggressive behaviour is accompanied by antisocial attitudes, ways of thinking, and behaviours. This small group of individuals commit from 50\% to $71 \%$ of the violent crimes that are committed (Hodgins, 1994; Moffitt et al., 2002). Importantly, while the rates of violence vary greatly across nations, the characteristics of persistent violent offenders do not (Wikström and Svensson, 2008).

Different labels have been applied to these persons. The medical model would diagnose them as having early-onset Conduct Disorder (CD) followed by Antisocial Personality Disorder (APD) in adulthood. In the criminology field, they are referred to as Life-Course Persistent Offenders (Moffitt et al., 2002). In research on personality, they are described as being high on the externalizing spectrum (Krueger et al., 2005), while in psychological studies a proportion of them are described as being high on psychopathy traits and a small number as presenting the syndrome of psychopathy (Hare and Neumann, 2006). Results of studies using one or other of these labels are not often considered by researchers using another label, 
thereby hindering efforts to more fully understand these persistently violent individuals. Throughout, we will refer to this population as individuals presenting stable antisocial behaviour (sASB).

The extant literature provides robust evidence of persistence of the antisocial and aggressive behaviours from a young age through middle adulthood (Odgers et al., 2007). Through three decades of life, outcomes are similar in females and males (Moffitt et al., 2001). In adulthood, in addition to violence and antisocial behaviour, these individuals display substance misuse, other mental health problems, and physical illnesses at much higher rates than the general population (Odgers et al., 2007, 2008). A good deal is known about the environmental factors that contribute to establishing this lifelong pattern of behaviour. These include poor parenting practices and physical abuse, characteristics of the parents notably, a young, poorly educated mother, a father displaying antisocial behaviour, living in a socially disadvantaged neighbourhood, and peers who themselves are engaging in antisocial behaviour (Farrington and West, 1993; Hodgins et al., 2001; Moffitt et al., 2002; Fergusson et al., 2005). Behavioural-genetic studies have shown that this life-long pattern of antisocial behaviour is moderately heritable (Moffitt, 2005), that substance misuse is one heritable aspect of ASB (Krueger et al., 2002), and that sASB measured in adulthood is more strongly heritable than conduct disorder in childhood (Lyons et al., 1995).

\section{KNOWLEDGE OF AETIOLOGICAL MECHANISMS TO INFORM TREATMENT DEVELOPMENT}

Knowledge of the neurobiological mechanisms that initiate and that maintain antisocial and aggressive behaviour across the lifespan is urgently needed to establish interventions that effectively reduce aggressive behaviour. Rehabilitation programs that target these mechanisms have not been developed (McGuire, 2009). While programmes for adults with sASB are needed, the priority is early childhood interventions. Aggressive and antisocial behaviours in childhood have negative consequences on relationships with parents, teachers and peers, academic performance, self-esteem, and on the development of pro-social behaviours. Thus it is essential to reduce the aggressive behaviours before these other negative consequences develop and progressively isolate such children from positive socialising experiences. The second reason for prioritizing the development of interventions with young children is the belief that the scope for changing behaviour, emotion processing, and the brain may be greatest in the early years, as may be the opportunities for limiting the effects of genes that confer vulnerabilities for sASB.

There is a now robust evidence that parent-training programmes are effective in reducing conduct problems in young children. And, importantly, there is emerging evidence that conduct problems among children with callous-unemotional traits may be reduced by teaching parents to use rewards, rather than punishment, to guide the child's behaviour (Hawes and Dadds, 2005). By contrast, there is no evidence that adults with psychopathy benefit from offender rehabilitation programmes (McGuire, 2009). The notion that emotion processing in children is readily modifiable is supported by a wealth of evidence documenting change after cognitive-behavioural interventions among children with emotional problems (Ishikawa et al., 2007). The belief that the brain is more malleable in childhood is based largely on studies of brain plasticity, discussed in the section "Brain Imaging Studies of Children". Finally, intervening to eradicate specific environmental factors, such as maltreatment, that interact with specific genes to confer vulnerabilities for sASB, would protect genetically vulnerable children from the biological and psychological consequences of the environmental factor (Lupien et al., 2009).

\section{FIVE CHALLENGES TO RESEARCH ON THE NEUROBIOLOGY OF PERSISTENT VIOLENCE}

Presently, five challenges hinder progress towards the goal of identifying the aetiological mechanisms that promote persistent violent behaviour. The first challenge confronting scientists is to develop hypotheses based on a thorough understanding of all available literatures relevant to the study of antisocial behaviour and to design studies that test alternate hypotheses. This strategy is the most likely to produce robust evidence. The second challenge is to study samples that are homogeneous with respect to variables that may be linked to neurobiological mechanisms underpinning violent behaviour. As we will show below, currently the field is failing to meet this challenge. The third challenge is to use reliable and valid measures in order to fully characterize participants so that the external validity of the results is evident. The fourth challenge is to restrict the range of age of participants, especially in studies of children and adolescents, so as not to confound developmental changes with group differences. And the final challenge is to take account of sex. While sASB is less common among females than males and the patterns of antisocial behaviour and outcomes in adulthood are similar (Moffitt et al., 2002; Odgers et al., 2008), available evidence suggests that the neurobiological mechanisms underpinning these behaviours differ in males and females. In the paragraphs that follow, each challenge will be discussed using examples from recent studies and suggestions will be made for meeting the challenge and improving research into the neurobiological mechanisms that underpin sASB.

\section{THEORETICALLY DRIVEN RESEARCH}

Research will advance understanding of the causes of violence if hypotheses are grounded in previous findings and studies designed to test alternate explanations. This implies that in order to conduct research on the neurobiological mechanisms underlying sASB, two expertises are needed, one on the phenotype and the other on the technologies used to examine neurobiological factors. Allowing the presence of a new technology, such as a magnetic resonance imager to drive research is unhelpful as the phenotype may not be well characterized resulting in misleading findings.

\section{HETEROGENEITY OF THE POPULATION OF INDIVIDUALS WHO DISPLAY STABLE ANTISOCIAL BEHAVIOUR ACROSS THE LIFE-SPAN BEHAVIOURS}

Most neurobiological studies have failed to distinguish sub-types within the sASB population. The exceptions are studies that focus on men with the syndrome of psychopathy and children with both conduct problems and callous-unemotional traits. We have argued that the extant literature suggests that within the sASB population there are subgroups that differ as to the neurobiological mechanisms that underlie their persistent aggressive behaviour (Hodgins, 2007; De Brito and Hodgins, 2009a). 


\section{$s A S B$ and anxiety}

As presented in Figure 1, approximately one-half of this population present elevated levels of anxiety. In a meta-analysis, the prevalence of anxiety disorders among children with CD has been estimated to be $3.1(95 \% \mathrm{CI})$ times higher than among children without CD (Angold et al., 1999). Among children with CD identified in community samples, the prevalence of co-morbid anxiety disorders ranges from $22 \%$ to $33 \%$, while among clinical samples of children with CD $60 \%$ to $75 \%$ present anxiety disorders (Russo and Beidel, 1994). The association between CD and anxiety varies by age and gender (Marmorstein, 2007) and is observed as early as 24 months (Gilliom and Shaw, 2004). Not all of the evidence is consistent. In a prospective study of a birth cohort, among those with anxiety disorders at age 32, only the individuals with post traumatic stress disorder had presented elevated rates of CD in childhood (Gregory et al., 2007). Further, a study of incarcerated adolescents found that among males the presence of generalized anxiety disorder lowered the risk of transition to APD 3 years later (Washburn et al., 2007).

Recent epidemiological investigations of large community samples have observed that approximately half of adults with APD present anxiety disorders. The National Comorbidity Survey studied a representative sample composed of 5,877 adults from 48 of the US states (Goodwin and Hamilton, 2003). More than half, 53.3\%, of those with APD received a lifetime diagnosis of an anxiety disorder. These findings were replicated in two large general population samples, one from the US and one from Canada (Sareen et al.,
2004). The researchers found that $47 \%$ of adults with APD, or with a history of $\mathrm{CD}$, or who presented only the adult criteria for APD, presented at least one life-time anxiety disorder. The associations between APD, CD and adult-only APD and anxiety disorders remained significant after controlling for socio-demographic characteristics, depression, and alcohol and drug use disorders. More recently, in a large US community sample, the 12-month prevalence of any anxiety disorder among individuals with APD reached $47.5 \%$ (Lenzenweger et al., 2007).

Secondary analyses of data from the National Household Survey of Great Britain showed that among respondents with APD, similar proportions of those with and without a co-morbid neurotic disorder reported engaging in violence towards others. Those with co-morbid neurotic disorders were more likely, however, to report assaulting other family members, people known to them, and their children (J.W. Coid, personal communication, February 13, 2007). We examined a randomly selected sample of male prisoners with sentences of 2 years or longer. After excluding those with severe mental illness and neurological disorders, we retained a sample of $232(46.9 \%)$ who met DSM-III-R criteria for APD. More than two-thirds (68\%) of the offenders with APD met criteria for at least one anxiety disorder, not including PTSD, and this rose to $69 \%$ when PTSD was included. The most common disorder was generalized anxiety disorder displayed by $58 \%$ of the offenders with APD. Importantly, in more than one-half of the cases of APD + anxiety, the anxiety disorders had onset prior to age 16 . There were no differences in the mean numbers of convictions for non-violent

\section{High levels of anxiety No psychopathic traits}

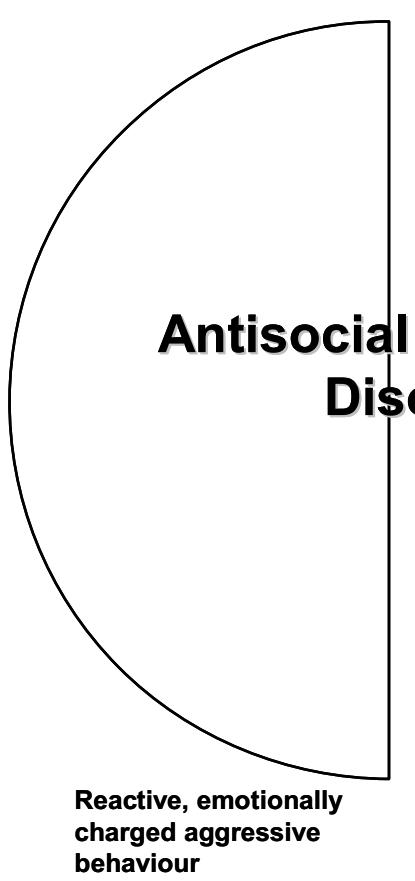

\section{Low levels of anxiety Psychopathic traits}

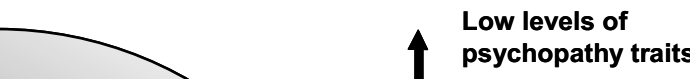

FIGURE 1 |The population of persons with early-onset antisocial behaviour that remains stable across the life-span. Originally published in De Brito and Hodgins (2009a) with permission from Wiley-Blackwell. 
offences or for violent offences, nor in the mean age at first conviction between the APD prisoners with and without anxiety disorders (Hodgins, De Brito, Chhabra, and Côté, under review).

We hypothesize that it is this anxious sub-group of individuals with sASB who display high levels of impulsivity, frequent nonviolent offending, and lower than average intelligence. Further, we have hypothesized that among males, it is this sub-type who carry the low activity variants of the MAOA gene and/or the serotonin transporter (5HTTLPR) (De Brito and Hodgins, 2009a). These genes are associated with low serotonergic turnover that has long been known to be associated with reactive violence (Virkkunen et al., 1995). In healthy men, the low activity variant of the MAOA gene is associated with enhanced reactivity to threat observed in the left amygdale, cingulate cortex, left insular cortex, and lateral OFC, an increased tendency to experience anger, frustration and bitterness, and reduced sensitivity to cues that elicit and maintain prosocial behaviour. Further, only in men, the low activity variant of MAOA has been found to be associated with compromised connectivity between the amygdala and the OFC and with a significant difference in volume of the OFC. These functional and structural differences have been interpreted to suggest that the low activity variant of the MAOA gene in men results in a reduced capacity of the orbital frontal cortex to regulate exaggerated responsiveness to aversive stimuli in limbic structures (Meyer-Lindenberg et al., 2006; Buckholtz and Meyer-Lindenberg, 2008). In males, the low activity variant of MAOA gene has been associated with sASB in the presence of maltreatment in childhood (Kim-Cohen et al., 2006). The low activity allele of the serotonin transporter, 5-HTTLPR, has also been associated with sASB, but it is unclear if the vulnerability conferred by this allele interacts or adds to maltreatment during childhood (Reif et al., 2007).

Maltreatment in childhood is known to alter HypothalamicPituitary-Adrenal (HPA) axis reactivity making individuals chronically hyper-reactive to their environments (Lupien et al., 2009) and both maltreatment and high cortisol levels have been linked to impulsive non-planfullness and external blame attribution (Cima et al., 2008). Maltreatment has also been shown to modify transcription of a gene, NR3C1 promotor, in the hippocampus that lead to HPA hyperreactivity (McGowan et al., 2009). Such alterations to the HPA axis could reinforce or even initiate a tendency to view others as hostile and thereby underlie persistent aggressive behaviour (Kruk et al., 2004). In adulthood, this would result in an individual who perceives others as threatening and who is emotionally labile. Violence towards others would be reactive and impulsive, in response to a feeling of being threatened.

\section{sASB and no anxiety}

As depicted in Figure 1, we hypothesize that the other half of the sASB population, approximately $2.5 \%$ of males, is composed of individuals who present higher levels of psychopathic traits, as illustrated by the distributions of scores on the PCL-R in offender populations (Hare, 1991) and lower than average levels of anxiety. Low tonic levels of skin conductance and cortisol are associated with the presence of psychopathic traits as well as with the syndrome of psychopathy (Holi et al., 2006; Cima et al., 2008). We hypothesize that it is children with conduct problems, lower than average levels of anxiety and cortisol (Loney et al., 2006), callousunemotional traits, and deficits in processing emotions, most particularly fear, who develop into the adults who constitute this half of the population (Frick and White, 2008). Further, it is in this subtype that callousness releases the usual constraints on aggressive behaviour and leads to cold premeditated aggressive behaviour (see Blair et al., 2005 for a review). Buried within this half of the population are the rare individuals who present the full-blown syndrome of psychopathy that is estimated to characterize less than $1 \%$ of men (see Kiel, this issue). As discussed below, there are no behavioural-genetic studies of the syndrome of psychopathy. Twin data suggest, however, that conduct problems are highly heritable in children with callous-unemotional traits and that this heritability is not explained by co-occurring hyperactivity symptoms (Viding et al., 2005, 2008).

\section{Attention deficit hyperactivity disorder}

Attention Deficit Hyperactivity Disorder (ADHD) is presented by many children within the sASB population (Biederman et al., 2008, for review see Vloet et al., 2006, 2008). The reasons for the high comorbidity of conduct problems and ADHD are presently unknown (Liu et al., 2004). Findings from behavioural-genetic studies indicate the existence of a "true hybrid" of CD/ADHD (Thapar et al., 2007) and also of cases of "true co-morbidity" with different genetic effects for each disorder (Rhee et al., 2008). Pure ADHD and pure $\mathrm{CD}$ are characterized by distinct genetic polymorphisms (Langley et al., 2008) and structural and functional brain abnormalities (Seidman et al., 2005; Sonuga-Barke, 2005; Durston and Konrad, 2007; Rubia et al., 2008, 2009). Recent functional imaging studies have addressed this issue by comparing children with only CD and children with only ADHD (Rubia et al., 2008, 2009) and young adolescents with callous-unemotional traits and with ADHD (Finger et al., 2008; Marsh et al., 2008).

\section{Heterogeneity of samples in brain imaging studies}

Thus, the extant literature suggests that the population of individuals who display sASB may be heterogeneous with respect to the neurobiological mechanisms that underlie their persistent violent behaviour. To date, this heterogeneity has largely been ignored in genetic and magnetic resonance imaging studies of brain structure (sMRI) and function (fMRI). The fact that these latter studies include small samples of subjects compounds the problem.

For example, Sterzer et al., (2005) used fMRI and compared 13 boys with severe CD and 13 healthy boys aged 9-15 years old. The boys with CD differed from the healthy boys in several ways: lower socio-economic status, lower IQ scores, and higher scores for anxiety, depression, attention problems, and aggressive behaviour. Activity in the amygdala during viewing of negatively valenced pictures as compared to neutral pictures was positively correlated with scores for anxiety and depression and negatively correlated with scores for aggressive behaviour. These results suggest that among the CD boys there were two sub-groups, one with and one without elevated levels of anxiety, who had distinctive amygdala reactions to the negative pictures. If the authors had not taken care to measure anxiety and aggression scores, in addition to distinguishing groups by the presence or absence of the diagnosis of $\mathrm{CD}$, and to relate these measures to brain function, their study may have lead 
to a misunderstanding of brain function among boys with CD. Instead, their findings are valuable in illustrating the importance of distinguishing subgroups of children with CD.

As mentioned above, it is now well established that there is high co-morbidity between SASB and ADHD and that ADHD is associated with specific brain abnormalities (Shaw et al., 2007). Several structural brain imaging studies conducted on children and adults with sASB, however, have not taken into account the impact of this co-morbid disorder on their results. This raises the possibility that differences attributed to $\mathrm{ASB}$ are partly attributable to ADHD or to a separate syndrome of $\mathrm{SASB}+\mathrm{ADHD}$. Studies that have considered ADHD as a potential nuisance variable have usually adopted one of two strategies in an attempt to untangle the associations of each disorder with brain pathology. Some studies have controlled for ADHD in making comparisons of brain structures using analysis of co-variance (ANCOVA), while other studies have matched groups with and without SASB on the presence of ADHD. We have recently outlined the theoretical and practical considerations pertaining to each of these approaches in the context of sMRI studies of sASB. (De Brito et al., 2009a). Specifically, ANCOVA presents challenges with regards to underlying statistical assumptions and the interpretation of the results. The matched-group design poses problems, as matching experimental groups on ADHD may un-match them on other unidentified variables of importance, thereby limiting the external validity of the results. Using our own data from a sMRI study of boys with sASB and callous-unemotional traits, we demonstrated empirically how researchers should check the impact of the inclusion or exclusion of ADHD symptoms as a covariate on their results (De Brito et al., 2009a).

\section{Conclusion}

We propose that sMRI and fMRI studies on children with conduct problems and violent adults have examined samples that are heterogeneous with respect to genetically driven brain mechanisms underpinning violent behaviour. This contributes to failures to replicate findings. By contrast, the results of studies that have focused on well defined sub-types within this population, for example children or adolescents with callous-unemotional traits, are more consistent (e.g. Marsh et al., 2008; De Brito et al., 2009b; Jones et al., 2009), but as noted above are still plagued by problems associated with identifying adequate strategies for dealing with co-morbid conditions such as ADHD and lower than average IQ (De Brito et al., 2009a), and, as discussed below, by problems in measuring the phenotype and identifying an appropriate comparison group.

\section{ASSESSMENTS OF STUDY PARTICIPANTS \\ Measuring antisocial behaviour and callous-unemotional traits in children and adolescents}

Even when studies focus on sub-groups within the sASB population, measurement of the phenotype remains a challenge. Measures have been developed to assess psychopathic traits among children. These are referred to as callous-unemotional (CU) traits, primarily a lack of remorse and empathy. CU traits show reasonable stability (correlations between scores ranging from $\sim 0.55$ to 0.7 ) over several years commencing in early childhood, but the long-term stability from early childhood to adult life is unknown. CU traits in childhood are associated with more severe antisocial behaviour (Frick and White, 2008), a poorer response to parenting programmes for conduct problems (Hawes and Dadds, 2005), and impaired response to emotional cues, particularly fear (Frick and White, 2008). The majority of research has used parent and teacher questionnaires to assess CU traits, e.g., the Antisocial Processes Screening Device (Frick and Hare, 2001), which usually have good psychometric properties but that do not allow more focused exploration of the phenomenology in childhood.

Several methodological issues may have important implications for characterizing CU traits. First, measurement of psychopathology in children frequently uses information gained from different sources, including the child, parents and other involved adults such as teachers. It is well-recognized that informants differ in their reports; correlations between parents (mothers versus fathers, teachers and professionals are usually around 0.3-0.4 (Achenbach et al., 1987). Variation is likely due to many factors, including individual expectations for behaviour and variation in actual behaviour across situations. In relation to longitudinal stability, cross-time, within-informant (parents) stability is much greater $(0.5-0.7)$ that cross-time, cross-informant (different teachers) $-\sim 0.2$ (Obradovic et al., 2007). There is much debate regarding the most appropriate method for combining conflicting information; Loeber et al., 1989) have argued with regard to disruptive behaviour that if any single informant endorses an item, the behaviour should be considered to be present. This makes good sense with discrete and often covert behaviours (where adolescents may reveal delinquent acts of which their parents are unaware). However, this approach may be more problematic when judgment or attribution plays a role in ratings. Multi-informant latent variables have also been used, but disadvantages include the lack of external specification of relative weightings given to different informants and variation in the latent variable from one population to another, making comparisons difficult. There is no consensus about which informants to use in the measurement of CU traits or how they should be combined. Further, the differing approaches adopted across studies may increase the heterogeneity across different samples.

A second source of heterogeneity is the actual measures used to identify CU traits. Many recent studies have used the Antisocial Processes Screening Device (APSD, Frick and Hare, 2001) but other influential studies have employed a variety of other measures, including briefer bespoke questionnaires (Moran et al., 2008) and measures incorporating limited questions from the APSD with other items on absence of prosocial behaviour (Dadds et al., 2005; Viding et al., 2005). There is little information on the extent to which these measures identify the same group of children.

\section{Measuring psychopathy among adults}

Most studies now use the Psychopathy Checklist Revised (PCL-R) (Hare, 1991) to assess the syndrome of psychopathy in adults. It is a difficult and time consuming task to complete this instrument if it is done as recommended and to a standard that achieves high levels of inter-rater reliability. Assessing psychopathy requires a great deal of information from multiple sources, (other than the individual in question) that documents the individual's behaviour since childhood. Most studies of psychopathy are conducted with offenders in prison or on probation and consequently, the validity of the psychopathy ratings depend to a very large degree on the quality 
of the criminal justice system files. The ratings also depend on the training, experience, and skill of the rater to integrate information from files and from interviews to assess personality traits.

\section{Categories or dimensions?}

As depicted in Figure 1, we hypothesize that approximately one-half of the SASB population present higher than average traits of psychopathy, but not the full blown syndrome. The extent to which psychopathy traits are dimensional is uncertain. Many studies of children, especially those using general population samples, have defined a sub-group with conduct problems and CU traits by imposing a cutoff on the measure of $\mathrm{CU}$ traits that identifies the top $5-10 \%$ of scorers. While evidence is accumulating to show that the risks associated with $\mathrm{CU}$ traits are continuously distributed in the population, presently it is not known whether neurobiological abnormalities associated with psychopathy are manifest only in an extreme group or are dimensionally related to the continuum of CU traits.

In order to study psychopathic traits in community samples, several self-report measures of psychopathy, such as Levenson Primary and Secondary Psychopathy Scales (LPSP, Levenson et al., 1995), Self-Report Psychopathy Scale-Revised (SRP-II; Williams and Paulhus, 2004), and Psychopathic Personality Inventory (PPI; Lilienfeld and Andrews, 1996) have been developed. These measures show convergent validity with measures of normal-range personality traits and DSM-IV personality disorder features (Lilienfeld and Fowler, 2006). Scores on the PPI correlate moderately to highly with the PCL-R affective and interpersonal ratings. The Youth Psychopathy Inventory (YPI) (Andershed et al., 2002) was developed to assess core psychopathic features in youth and facets of YPI show moderate correlations with the corresponding facets of PCL youth version (Andershed et al., 2007). Since pathological lying is a criterion for the syndrome of psychopathy, caution in the use of self-report is warranted, especially when assessing individuals who may present high levels of psychopathic traits. More studies are required in validating self-report measures against ratings made using the PCL-R based on reliable documentation of the individual's history of antisocial behaviour.

A number of researchers have advocated measurement of psychopathy using "normal" personality characteristics, such as the socalled Big Five (Lynam and Derefinko, 2006). Although it appears possible to capture most aspects of psychopathic personality using ratings derived from standard personality assessments, such assessments do not often assess the emotional detachment that characterizes psychopathy (Rutter, 2005).

Even within this one sub-group of the sASB population, our limited understanding of the phenotype and how to measure the phenotype, impacts neurobiological investigations. For example, presently there is no evidence about the heritability of the syndrome of psychopathy. But several behavioural-genetic studies have been conducted examining the heritability of psychopathic traits in children and adolescents measured using self-reports (YPI, PPI) and parent and teacher reports of CU traits (Viding and Larsson, in press; Blonigen et al., 2003). All reported moderate to high heritability of psychopathic traits. The extent to which these findings relate to the syndrome of psychopathy remains unknown.

\section{Comparison groups}

There are many studies of cognitive and emotional processing among offenders with psychopathy, and recently structural and functional imaging studies. There is a consensus among researchers on the definition of the syndrome of psychopathy and the use of the PCL-R (Hare, 1991). Understanding the results of these studies, however, is limited because often the comparison group is poorly described. For example, in many of the studies of neuropsychological test performance, the comparison group is made up of offenders who do not meet the diagnostic cut-off for psychopathy on the PCL, while in other studies the comparison group includes offenders with low PCL scores. This already complicates understanding of the features that distinguish the psychopathic offenders (De Brito and Hodgins, 2009b). Further, if among the sASB offenders without the syndrome of psychopathy, there are two sub-types - those with and without anxiety - who differ as to the neurobiological mechanisms underlying persistent violent behaviour, then understanding the results of comparisons becomes more difficult. In recent brain imaging studies, offenders with psychopathy were compared to healthy men. Key characteristics such as PCL and IQ were not measured in the healthy men, only for the offenders with psychopathy (Tiihonen et al., 2008). Consequently, reports of features that distinguish offenders with psychopathy are difficult to aggregate and interpret.

\section{Conclusion}

Presently brain imaging studies of the SASB population, those of children and adults, have examined samples that differ as to the proportions of the different sub-types that were included. We and others (Buckholtz and Meyer-Lindenberg, 2008) have hypothesized that the sub-types within the sASB population differ as to the genetically driven neural mechanisms that promote persistent violent behaviour. If this hypothesis is correct, then it will be necessary to select samples that are homogeneous with respect to key features that distinguish these sub-types in order to further understanding of the gene-brain mechanisms.

\section{AGE}

\section{Brain imaging studies of adults}

Studies of the brains of persistently violent adults provide information about the mechanisms that support on-going behaviour, emotion processing, etc, and provide only clues about aetiological mechanisms. As an abundance of research shows, individuals with sASB exhibit distinct patterns of behaviour, temperament, cognitive function, and emotion processing early in life that is conferred, at least in part, by genes. The genes act by modifying brain structures and/or functions. But important to consider, is that the child's brain has the capacity to re-organize as a result of an initial insult or abnormality. The most striking example of the extent of plasticity is presented by individuals who as children undergo hemispherectomy for intractable epilepsy. With only one hemisphere, many of these children grow up to complete baccalaureate degrees, and exhibit good records of employment, psychosocial functioning, and are able to dance, run, and play ping-pong (Kossoff et al., 2003). Consequently, when studying adult brains, it is necessary to understand that we are not viewing the "original abnormality" but rather what may have resulted from early abnormalities. Further, 
adults who exhibit sASB have long histories of alcohol and illicit drug use and of fighting, all of which may alter brain structure and function (Chanraud et al., 2007; Sim et al., 2007). The use of substances is in almost all cases so extensive that it is impossible to assess key variables such as type of substance, dose, time during development when each substance was used, and combinations of substances consumed. Further, little is known of the effects of many of these substances and combinations on the brain at different stages of development.

\section{Brain imaging studies of children}

By comparison, studying children has many advantages, but also disadvantages. When studying children with conduct problems, we presently have no way of knowing which ones will become persistent violent offenders (Simonoff et al., 2004). Thus samples of children with CD are heterogeneous as they likely include both those who will persist and those who will desist. A second disadvantage of studying children is that recruitment depends on their parents. The parents of children with conduct problems are more likely than parents of healthy children to be young, poorly educated, exhibit antisocial behaviour, depression, and poor parenting practices (Moffitt et al., 2002) and are relatively difficult to engage in treatment to reduce their child's conduct problems (Scott et al., 2001). Consequently, parental characteristics may influence recruitment and thereby lead to the recruitment of samples of children with conduct problems that are not representative of the population of children with conduct problems. Another disadvantage of using MRI to study children is that many children find it difficult to stay still in the scanner resulting in significant numbers of unusable scans.

Finally, a further disadvantage, or more exactly an impediment, to studying children is that presently we are only beginning to learn about the complexity and non-linearity of brain development (Paus et al., 2008). A recent longitudinal study of brain development among healthy individuals followed from ages 4 to 21 revealed that grey matter volume decreases in several cortical areas from early childhood to young adulthood in a linear, but region specific manner, (Gogtay et al., 2004). These findings show, for example, that there are significant structural differences in the brains of 10 and 17 year olds. In a recent study of brain morphology, posthoc analyses indicated that among typically developing boys grey matter concentration in the medial OFC and the left dorsal anterior cingulate cortex decreased from age 10 to 13.5 years, consistent with previous studies. By contrast, among boys with conduct problems and callous-unemotional traits, during this same age period, grey matter concentration in the medial OFC remained stable, while in the left dorsal anterior cingulate cortex it increased (De Brito and Hodgins, 2009a). Thus, cross-sectional sMRI studies with a wide age range of participants risk confounding developmental changes with group differences (Wilke and Holland, 2008). Most of the published studies of brain morphology among children with conduct problems have included participants who varied widely in age (e.g., 9.75-20.5 years in Kruesi et al., 2004; 12-17 years in Huebner et al., 2008; 9-15 years in Sterzer et al., 2007). Although all studies matched groups for age, the distributions of the ages of the children within each group were not reported. This may have led to misinterpretation of apparent group differences.

\section{Genetic studies at different stages of development}

Behavior genetic studies show that the relative importance of genetic and environmental influences may change over time. The cross-sectional and retrospective-longitudinal findings suggest that genetic influences may be more important in adult than child antisocial behaviour (Lyons et al., 1995). A number of mechanisms may play a role; in behavioural development generally, heritability estimates increase with age and one explanation has been the increasing importance with age of gene-environment correlation (Scarr and McCartney, 1983). Furthermore, genes can switch on and off at different points in development and gene-environment interaction provides a further mechanism for genetic influences to increase over time (Moffitt et al., 2005). With respect to antisocial behaviour, ADHD (Simonoff et al., 2004) and CU traits (Frick and Viding, 2009) are both predictors of persistent antisocial behaviour and both have moderate to strong heritabilities, suggesting that the more heritable subtypes of sASB may be the ones that are more likely to persist into adulthood.

\section{Taking account of developmental stages}

Evidence suggests that both genetic (Buckholtz and MeyerLindenberg, 2008) and environmental factors associated with subtypes within the sASB population impact neural systems at critical periods during development. The time during the course of development when these factors are active appears to alter the effects that they have on the brain. For example, the age at which maltreatment occurs determines the consequences on hypothalamic-pituitaryaxis functioning (Lupien et al., 2009). Further, the brain changes with age in ways that are still unclear. There are three important consequences of this knowledge for research aiming to elucidate the mechanisms promoting persistent violence. One, measuring biological rather than chronological age may provide more meaningful results, as has been shown in studies of antisocial girls (Magnusson, 1988). Two, in order to elucidate the aetiology of the different subtypes of sASB, it is essential to determine the age at which genetic and environmental factors act to modify brain structure and/or functioning. Three, in order to determine the mechanisms that maintain persistent violent behaviour, it is essential to compare participants with and without sASB of the same biological age in order to take account of brain development.

\section{SEX MATTERS}

Results from prospective, longitudinal studies consistently report that while there are fewer females than males who exhibit an early onset stable pattern of antisocial behaviour, at different periods during the course of development behaviours and characteristics of men and women with sASB are similar (Moffitt et al., 2001). Yet evidence is accumulating to suggest that within the different sub-groups, the neurobiological mechanisms underpinning the patterns of violence differ. A recent investigation confirmed results of many older studies in showing that the impact of environmental factors on sASB varied by gender. Genetic factors were more important in girls, while in boys it was largely mediated by environmental variables (D'Onofrio et al., 2007). While the low activity variant of the MAOA gene has been consistently associated with persistent antisocial and aggressive behaviour in males, results with females are inconsistent (Sjöberg et al., 2007; 
Ducci et al., 2008). Further, in men only, this genetic variant was associated with abnormalities in OFC-amygdala connectivity and increased OFC volume in healthy men suggestive of compromised OFC regulation of limbic responses (Meyer-Lindenberg et al., 2006; Buckholtz this issue). Similarly, the serotonin transporter (5-HTTPLR) has been shown to affect amygdala-ventromedial prefrontal cortex connectivity in males only (Heinz et al., 2005). Within the sub-group displaying sASB and psychopathic or callous-unemotional traits, low cortisol levels have been consistently found to distinguish the men, but not women (Loney et al., 2006; O'Leary et al., 2007).

Almost all of the MRI studies of persistently violent offenders have included only men or have examined mixed samples without specifically examining the effect of sex (Finger et al., 2008; Marsh et al., 2008). Importantly, however, the key brain areas associated with persistent violence, limbic circuit and dorsal and orbital frontal cortices differ in relative size in males and females. These structural

\section{REFERENCES}

Achenbach, T. M., McConaughy, S. H., and Howell, C. T. (1987). Child/adolescent behavioral and emotional problems: implications of crossinformant correlations for situational specificity. Psychol. Bull. 101, 213-232.

Angold, A., Costello, E. J., and Erkanli, A. (1999). Comorbidity. J. Child. Psychol. Psychiatry 40, 57-87.

Andershed, H., Hodgins, S., and Tengström, A. (2007). Convergent validity of the youth psychopathic traits inventory (YPI): association with the Psychopathy Checklist: Youth Version. Assessment 14, 144-154.

Andershed, H., Kerr, M., Stattin, H., and Levander, S. (2002). Psychopathic traits in non-referred youths: initial test of a new assessment tool. In Psychopaths: Current International Perspectives, E. Blaauw and L. Sheridan, eds (The Hague, Elseiver), pp. 131-158.

Biederman, J., Petty, C. R., Dolan, C., Hughes, S., Mick, E., Monuteaux, M. C., and Faraone, S. V. (2008). The longterm longitudinal course of oppositional defiant disorder and conduct disorder in ADHD boys: findings from a controlled 10-year prospective longitudinal follow-up study. Psychol. Med. 38, 1027-1036.

Blair, J., Mitchell, D., and Blair, K. (2005). The Psychopath: Emotion and the Brain. Malden, MA, Blackwell Publishing.

Blonigen, D. M., Carlson, S. R., Krueger, R. F., and Patrick, C. J. (2003). A twin study of self-reported psychopathic personality traits. Pers. Individ. Dif. 35, 179-197.

Buckholtz, J. W., and Meyer-Lindenberg, A. (2008). MAOA and the neurogenetic architecture of human aggression. Trends Neurosci. 31, 120-129.
Chanraud, S., Martelli, C., Delain, F. Kostogianni, N., Douaud, G., Aubin, H. J., Reynaud, M., and Martinot, J.-L. (2007). Brain morphometry and cognitive performance in detoxified alcoholdependentswith preserved psychosocial functioning. Neuropsychopharmacology 32, 429-438.

Cima, M., Smeets, T., and Jelicic, M. (2008). Self-reported trauma, cortisol levels, and aggression in psychopathic and non-psychopathic prison inmates. Biol. Psychol. 78, 75-86.

D’Onofrio, B. M., Slutske, W. S., Turkheimer, E., Emery, R. E., Harden, K. P., Madden, P. A., and Martin, N. G. (2007). Intergenerational transmission of childhood conduct problems: a children of twins study. Arch. Gen. Psychiatry 64, 820-829.

Dadds, M. R., Frost, A., Fraser, J., and Hawes, D. J. (2005). Disentangling the underlying dimensions of psychopathy and conduct problems in childhood: a community study. J. Consult. Clin. Psychol. 73, 400-410.

De Brito, S. A., and Hodgins, S. (2009a). Antisocial personality disorder. In Personality, Personality Disorder, and Violence: An Evidence Based Approach, M. McMurran and R. Howard, eds (Chichester, WileyBlackwell Publishing), pp. 133-153.

De Brito, S. A., and Hodgins, S. (2009b). Executive functions of persistent violent offenders: a critical review of the literature. In The Neurobiological Basis of Violence: Science and Rehabilitation, S. Hodgins, E. Viding, and A. Plodowski, eds (Oxford, Oxford University Press), pp. 167-199.

De Brito, S. A., Hodgins, S., McCrory, E. J. P., Mechelli, A., Wilke, M., Jones, A. P., and Viding, E. (2009a). Structural neuroimaging and the antisocial brain: main findings and

differences have been interpreted to suggest that in females, cortical dampening of activity in limbic structures may explain, in part, the lower rates of violent behaviour (Gur et al., 2002).

\section{CONCLUSION}

In order to develop effective interventions to reduce and prevent persistent violent behavior, knowledge of the neurobiological mechanisms underpinning this pattern of behaviour is urgently needed. Longitudinal prospective investigations of birth cohorts and general population samples have provided detailed descriptive information on the SASB population at different developmental stages. Currently, research aiming to identify neurobiological mechanisms is limited by a failure to test evidence-based hypotheses, to examine subtypes within this population who are hypothesized to be homogeneous with respect to mechanisms, to use valid and reliable measures to characterize study participants, and to take account of stages of development and sex.

methodological challenges. Crim. Justice Behav. 36, 1173-1186.

De Brito, S. A., Mechelli, A., Wilke, M. Laurens, K. R., Jones, A. P., Barker, G. J., Hodgins, S., and Viding, E. (2009b). Size matters: increased gray matter in boys with conduct problems and callous-unemotional traits. Brain 132, 843-852.

Ducci, F., Enoch, M.-A., Hodgkinson, C., Xu, K., Catena, M., Robin, R. W. and Goldman, D. (2008). Interaction between a functional MAOA locus and childhood sexual abuse predicts alcoholism and antisocial personality disorder in adult women. Mol. Psychiatry 13, 334-347.

Durston, S., and Konrad, K. (2007). Integrating genetic, psychopharamacological and neuroimaging studies: a converging methods approach to understanding the neurobiology of ADHD. Dev. Rev. 27, 374-395.

Farrington D. P., and West, D. J. (1993). Criminal, penal and life histories of chronic offenders: risk and protective factors and early identification. Crim. Behav. Ment. Health 3, 492-523.

Fergusson, D. M., Horwood, L. J., and Ridder,E.M. (2005). Show me the child at seven: the consequences of conduct problems in childhood for psychosocial functioning in adulthood. J. Child. Psychol. Psychiatry 46, 837-849.

Finger, E. C., Marsh, A. A., Mitchell, D. G., Reid, M. E., Sims, C., Budhani, S., Kosson, D. S., Chen, G., Towbin, K. E. Leibenluft, E., Pine, D. S., and Blair J. R. (2008). Abnormal ventromedial prefrontal cortex function in children with psychopathic traits during reversal learning. Arch. Gen. Psychiatry 65, 586-594.

Frick, P. J., and Hare, R. D. (2001). The Antisocial Processes Screening Device. Toronto, Multi-Health Systems.
Frick, P. J., and Viding, E. (2009). Antisocial behavior from a developmental psychopathology perspective. Dev. Psychopathol. 21, 1111-1131.

Frick, P. J., and White, S. F. (2008). The importance of callous-unemotional traits for the development of aggressive and antisocial behaviour. J. Child. Psychol. Psychiatry 49, 359-375.

Gilliom, M., and Shaw, D. S. (2004). Codevelopment of externalizing and internalizing problems in early childhood. Dev. Psychopathol. 16, 313-333.

Gogtay, N., Giedd, J. N., Lusk, L., Hayashi, K. M., Greenstein, D., Vaituzis, A. C., Nugent, T. F. III., Herman, D. H., Clasen, L. V., Toga, A. W., Rapoprot, J. L., Thompson, P. M., and Ungerleider, L. G. (2004). Dynamic mapping of human cortical development during childhood through early adulthood. Proc. Natl. Acad. Sci. U.S.A. 101, 8174-8179.

Goodwin, R. D., and Hamilton, S. P. (2003). Lifetime comorbidity of antisocial personality disorder and anxiety disorders among adults in the community. Psychiatry Res. 117, 159-166.

Gregory, A. M., Caspi, A., Moffitt, T. E., Koenen, K., Eley, T. C., and Poulton, R. (2007). Juvenile mental health histories of adults with anxiety disorders. Am. J. Psychiatry 164, 301-308.

Gur, R. C., Gunning-Dixon, F., Bilker, R. B., and Gur, R. E. (2002). Sex differences in temporo-limbic and frontal brain volumes of healthy adults. Cereb. Cortex 12, 998-1003.

Hare, R. D. (1991). The Hare Psychopathy Checklist - Revised. Toronto, MultiHealth Systems.

Hare, R. D., and Neumann, C. N. (2006). The PCL-R Assessment of psychopathy: development, structural properties, and new directions. In Handbook of 
Psychopathy, C.J.Patrick,ed.(New York, Guilford Press), pp. 58-88.

Hawes, D. J., and Dadds, M. R. (2005). The treatment of conduct problems in children with callous-unemotional traits. J. Consult. Clin. Psychol. 73, 737-741.

Heinz, A., Braus, D. F., Smolka, M. N., Wrase, J., Puls, I., Hermann, D., Klein, S., Grüsser, S. M., Flor, H., Schumann, G., Mann, K., and Büchel, C. (2005). Amygdala-prefrontal coupling depends on a genetic variation of the serotonin transporter. Nat. Neurosci. $8,20-21$.

Hodgins, S. (1994). Status at age 30 of children with conduct problems. Stud. Crime Crime Prev. 3, 41-62.

Hodgins, S. (2007). Persistent violent offending: What do we know? Editorial. Br. J. Psychiatry 190(Suppl. 49), s12-s14.

Hodgins, S., Kratzer, L., and McNeil, T. F. (2001). Obstetrical complications, parenting, and risk of criminal behavior. Arch. Gen. Psychiatry 58, 746-752.

Holi, M., Auvinen-Lintunen, L., Lindberg, N., Tani, P., and Virkkunen, M. (2006). Inverse correlation between severity of psychopathic traits and serum cortisol levels in young adult violent male offenders. Psychopathology 39, 102-104.

Huebner, T., Vloet, T. D., Marx, I., Konrad, K., Fink, G. R., Herpertz, S. C., and Herpertz-Dahlmann, B. (2008). Morphometric brain abnormalities in boys with conduct disorder. J. Am. Acad. Child Adolesc. Psychiatry 47, 541-548.

Ishikawa, S., Okajima, I., Matsuoka, H., and Sakano, Y. (2007). Cognitive Behavioural Therapy for anxiety disorders in children and adolescents: a meta-analysis. Child Adolesc. Ment. Health 12, 164-172.

Jones, A. P., Laurens, K. R., Herba, C. M., Barker, G. J., and Viding, E. (2009). Amygdala hypoactivity to fearful faces in boys with conduct problems and callous-unemotional traits. Am. J. Psychiatry 166, 95-102.

Kim-Cohen, J., Caspi, A., Taylor, A., Williams, B., Newcombe, R., Craig, I., and Moffitt, T. E. (2006). MAOA, maltreatment, and gene-environment interaction predicting children's mental health: new evidence and a meta-analysis. Mol. Psychiatry 11, 903-913.

Kossoff, E. H., Vining, E. P. G., Pillas, D. J., Pynik, P. L., Avellino, A. M., Carson, B. S., and Freeman, J. M. (2003). Hemispherectomy for intractable unihemispheric epilepsy: biology vs outcome. Neurobiology 6, 887-890.

Kratzer, L., and Hodgins, S. (1999). A typology of offenders: a test of
Moffitt's theory among males and females from childhood to age 30 . Crim. Behav. Ment. Health 9, 57-73.

Krueger, R. F., Hicks, B. M., Patrick, C. J., Carlson, S. R., Iacono, W. G., and McGue, M. (2002). Etiologic connections among substance dependence, antisocial behavior, and personality: modeling the externalizing spectrum. J. Abnorm. Psychol. 111, 411-424.

Krueger, R. F., Markon, K. E., Patrick, C. J., and Iaconi, W. G. (2005). Externalizing psychopathologyinadulthood:a dimensional-spectrum conceptualization and its implications for DSM-V. J. Abnorm. Psychol. 114, 5387-5550.

Kruesi,M.J.P., Casanova,M.F., Mannheim, G. 1., and Johnson-Bilder, A. (2004). Reduced temporal lobe volume in early onset conduct disorder. Psychiatry Res. Neuroimag. 132, 1-11.

Kruk, M. R., Halász, J., Meelis, W., and Heller, J. (2004). Fast positive feedback between the adrenocortical stress response and a brain mechanism involved in aggressive behavior. Behav. Neurosci. 118, 1062-1070.

Langley, K., Turic, D., Rice, F., Holmans, P., van den Bree, M. B. M., Craddock, N., Kent, L., Owen, M. J., O’Donovan, M. C., and Thapar, A. (2008). Testing for gene x environment interaction effects in attention deficit hyperactivity disorder and associated antisocial behavior. Am. J. Med. Genet. B Neuropsychiatr. Genet. 147B 1, 49-53.

Lenzenweger, M. F., Lane, M. C., Loranger, A. W., and Kessler, R. C. (2007). DSMIV personality disorders in the national comorbidity survey replication. Biol. Psychiatry 62, 553-564.

Levenson, M. R., Kiehl, K. A., and Fitzpatrick, C. M. (1995). Assessing psychopathic attributes in a noninstitutionalized population. J. Pers. Soc. Psychol. 58, 1073-1081.

Lilienfeld, S. O., and Andrews, B. P. (1996). Development and preliminary validation of a self-report measure of psychopathic personality traits in noncriminal populations. J. Pers. Assess. 66, 488-524.

Lilienfeld, S. O. and Fowler, K. A. (2006). The self-report assessment of psychopathy. In Handbook of Psychopathy, C. Patrick, ed. (New York, The Guildford Press), pp. 107-132.

Liu, J., Raine, A., Veneables, P. H., and Mednick, S. A. (2004). Malnutrition at age 3 and externalising behavior problems at ages 8,11 , and 17 years. Am. J. Psychiatry 161, 2005-2013.

Loeber, R., Green, S. M., Lahey, B. B., and Stouthamer-Loeber, M. (1989). Optimal informants on childhood disruptive behaviors. Dev. Psychopathol. 1,317-337.

Loney, B. R., Butler, M. A., Lima, E. N., Counts, C. A., and Eckel, L. A. (2006).
The relation between salivary cortisol, callous-unemotional traits, and conduct problems in an adolescent non-referred sample. J. Child. Psychol. Psychiatry 47, 30-36.

Lupien, S. J., McEwen, B. S., Gunnar,M. R. and Heim, C. (2009). Effects of stress throughout the lifespan on the brain, behaviour and cognition. Nat. Rev Neurosci. 10, 434-445.

Lynam, D. R., and Derefinko, K. J. (2006). Psychopathy and personality. In Handbook of Psychopathy, C. Patrick, ed. (New York, The Guildford Press), pp. 133-155.

Lyons, M. J., True, W. R., Elsen, S. A., Goldberg, J., Meyer, J. M., Faraone, S. V., Eaves, L. J., and Tsuang, M. T. (1995). Differential heritability of adult and juvenile antisocial traits. Arch. Gen. Psychiatry 52, 905-915.

Magnusson, D. (1988). Individual Development From An Interactional Perspective: A Longitudinal Study. New Jersey, Lawrence Erlbaum Associates.

Marmorstein, N. R. (2007). Relationships between anxiety and externalizing disorders in youth: the influences of age and gender. J. Anxiety Disord. 21, 420-432.

Marsh, A. A., Finger, E. C., Mitchell, D. G. V., Reid, M. E., Sims, C., Kosson, D. S., Leibenluft, E., Pine, D. S., and Blair, R. J. R. (2008). Reduced amygdala response to fearful expressions in children and adolescents with callous-unemotional traits and disruptive behavior disorders. Am. J. Psychiatry 165, 712-720.

McGowan, P. O., Sasaki, A., D’Alessio, A. C., Dymov, S., Labonte, B., Szyf, M., Turecki, G., and Meaney, M. J. (2009). Epigenetic regulation of the glucocorticoid receptor in human brain associates with childhood abuse. Nat. Neurosci. 12, 342-348.

McGuire, J. (2009). Reducing personal violence: risk factors and effective interventions. In The Neurobiological Basis of Violence: Science and Rehabilitation, S. Hodgins, E. Viding, and A.Plodowski, eds. (Oxford, Oxford University Press), pp. 287-327.

Meyer-Lindenberg, A., Buckholtz, J. W. Kolachana, B., Hariri, A. R., Pezawas, L., Blasi, G., Wabnitz, A., Honea, R. Verchinske, B., Callicott, J., Egan, M., Mattay, V., and Weinberger, D. (2006) Neural mechanisms of genetic risk for impulsivity and violence in humans. Proc. Natl. Acad. Sci. U.S.A. 103 6269-6274.

Moffitt, T. E. (2005). Genetic and environmental influences on antisocial behaviors: evidence from behavioralgenetic research. Adv. Genet. 55, 42-104.

Moffitt, T. E., Caspi, A., Harrington, H., and Milne, B. J. (2002). Males on the life-course-persistent and adolescencelimited antisocial pathways: follow-up at age 26 years. Dev. Psychopathol. 14, 179-207.

Moffitt, T. E., Caspi, A., and Rutter, M. (2005). Strategy for investigating interactions between measured genes and measured environments. Arch. Gen. Psychiatry 62, 473-481.

Moffitt, T. E., Caspi, A., Rutter, M., and Silva, P. A. (2001). Sex Differences in Antisocial Behaviour: Conduct Disorder, Delinquency, and Violence in the Dunedin Longitudinal Study. New York, NY, Cambridge University Press.

Moran, P., Ford, T., Butler, G., and Goodman, R. (2008). Callous and unemotional traits in children and adolescents living in Great Britain. Br. J. Psychiatry 192, 65-66.

Nelson, C. and Jeste, S. (2008). Neurobiological perspectives on developmental psychopathology. In Rutter's Child and Adolescent Psychiatry, M. Rutter, D. Bishop, D. Pine, S. Scott, J. S. Stevenson, E.A. Taylor, and A. Thapar, eds (Chichester, Wiley-Blackwell), pp. 157.

Obradovic, J., Pardini, D. A., Long, J. D., and Loeber, R. (2007). Measuring interpersonal callousness in boys from childhood to adolescence: an examination of longitudinal invariance and temporal stability. J. Clin. Child. Adolesc. Psychol. 36, 276-292.

Odgers, C. L., Caspi, A., Broadbent, J. M., Dickson, M. D., Hancox, R. J., Harrington, H. L., Poulton, R., Sears, M. R., Thomson, W. M., and Moffitt, E. T. (2007). Prediction of differential adult health burden by conduct problem subtypes in males. Arch. Gen. Psychiatry 64, 476-484.

Odgers, C. L., Moffitt, T. E., Broadbent, J. M., Dickson, N., Hancox, R. J., Harrington, H., Poulton, R., Sears, M. R., and Thomson, W. M. (2008). Female and male antisocial trajectories: from childhood origins to adult outcomes. Dev. Psychopathol. 20, 673-716.

O'Leary, M.M., Loney, B. R., and Eckel, L.A. (2007). Gender differences in the association between psychopathic personality traits and cortisol response to induced stress. Psychoneuroendocrinology 32, 183-191.

Paus, T., Keshavan, M., and Giedd, J. N. (2008). Shy do many psychiatric disorders emerge during adolescence? Nat. Rev. Neurosci. 9, 947-957.

Reif,A.,Rosler,M.,Freitag,C.M.,Schneider, M., Eujen, A., Kissling, C., Wenzler, D. Jacob, C. P., Retz-Junginger, P., Thorne, T., Lesch, K.-P., and Retz, W. (2007). Nature and nurture predispose to violent behavior: serotonergic genes and adverse childhood environment. 
Neuropsychopharmacology 32, 2375-2383.

Rhee, S. H., Willcutt, E. G., Hartman, C. A., Pennington, B. F., and DeFries, J.C. (2008). Test of alternative hypotheses explaining the comorbidity between attention-deficit/hyperactivity disorder and conduct disorder. J. Abnorm. Child Psychol. 36, 29-40.

Rubia, K., Halari, R., Smith, A. B., Mohammed, M., Scott, S., Giampietro, V., Taylor, E., and Brammer, M. J. (2008). Dissociated functional brain abnormalities of inhibition in boys with pure conduct disorder and in boys with pure attention deficit hyperactivity disorder. Am. J. Psychiatry 165 , 889-897.

Rubia,K.,Smith,A.B.,Halari, R., Matsukura, F., Mohammad, M., Taylor, E., and Brammer, M. J. (2009). Disorder-specific dissociation of orbitofrontal dysfunction in boys with pure conduct disorder during reward and ventrolateral prefrontal dysfunction in boys with pure ADHD during sustained attention. Am. J. Psychiatry 166, 83-94.

Russo, M. F., and Beidel, D. C. (1994). Comorbidity of childhood anxiety and externalizing disorders: prevalence, associated characteristics, and validation issues. Clin. Psychol. Rev. 14, 199-221.

Rutter, M. (2005). What is the meaning and utility of the psychopathy concept? J. Abnorm. Child. Psychol. 33, 499-503.

Sareen, J., Stein, M. B., Cox, B. J., and Hassard, S. T. (2004). Understanding comorbidity of anxiety disorders with antisocial behaviour: findings from two large community surveys. J. Nerv. Ment. Dis. 192, 178-186.

Scarr, S., and McCartney, K. (1983). How people make their own environments: a theory of genotype-environment effects. Child Dev. 54, 424-435.

Scott, S., Spendeer, Q., Doolan, M., Jacobs, B., and Aspland, H. (2001). Multicentre controlled trial of parenting groups for childhood antisocial behaviour in clinical practice. BMJ 323, 194.

Seidman, L. J., Valera, E. M., and Markis, N. (2005). Structural brain imaging of attention-deficit/hyperactivity disorder. Biol. Psychiatry 57, 1263-1272.

Shaw, P., Eckstrand, K., Sharp, W., Blumenthal, J., Lerch, J. P., Greenstein, D., Clasen, L., Evans, A., Giedd, J., and Rapoport, J. L. (2007). Attentiondeficit/hyperactivity disorder is characterized by a delay in cortical maturation. Proc. Natl. Acad. Sci. U.S.A. 104, 19649-19654.

Sim, M. E., Lyoo, I. K., Streeter, C. C., Covell, J., Sarid-Segal, O., Ciraulo, D. A., Kim, M. J., Kaufman, M. J., Yurgelun-Todd, D. A., and Renshaw, P. F. (2007). Cerebellar gray matter volume correlates with duration of cocaine use in cocaine-dependent subjects. Neuropsychopharmacology 32, 2229-2237.

Simonoff, E., Elander, J., Holmshaw, J., Pickles, A., Murray, R., and Rutter, M. (2004). Predictors of antisocial personality. Continuities from childhood to adult life. Br. J. Psychiatry 184, 118-127.

Sjöberg, R. L., Nilsson, K. W., Wargelius, H-L., Leppert, J., Lindström, L., and Oreland, L. (2007). Adolescent girls and criminal activity: role of MAOALPR genotype and psychosicial factors. Am. J. Med. Genet. B Neurospychiatr. Genet. 144B, 159-164.

Sonuga-Barke,E.J.S. (2005). Causal model of attention-deficit/hyperactivity disorder: from common simple deficits to multiple developmental pathways. Biol. Psychiatry 57, 1231-1238.

Sterzer, P., Stadler, C., Krebs, A., Kleinschmidt, A., and Poustka, F. (2005). Abnormal neural responses to emotional visual stimuli in adolescents with conduct disorder. Biol. Psychiatry 57, 7-15.

Sterzer P., Stadler, C., Poustka, F., and Kleinschmidt, A. (2007). A structural neural deficit in adolescents with conduct disorder and its association with lack of empathy. Neuroimage 37, 335-342.

Thapar, A., Langley, K., Owen, M. J., and O’Donovan, M. C. (2007). Advances in genetic findings on attention deficit hyperactivity disorder. Psychol. Med. 37, 1681-1692.

Tiihonen, J., Rossi, R., Laskso, M. P., Hodgins, S., Testa, C., Perez, J., RepoTiihonen, E., Vaurio, O., Soininein, H. Aronen, H.J., Kononen, M., Thompson, P., and Frisoni, G. B. (2008). Brain anatomy of persistent violent offenders: more rather than less. Psychiatr. Res. Neuroimag. 163, 201-212.

Viding, E., Jones, A. P., Frick, P. J., Moffitt, T. E., and Plomin, R. (2008) Heritability of antisocial behaviour at 9: do callous-unemotional traits matter? Dev. Sci. 11, 17-22.

Viding, E., and Larsson, H. (In press). Genetics of child and adolescent psychopathy. In Handbook of Youth Psychopathy, D. Lynam and R. Salekin, ed. (Guilford Press).

Viding, R., Blair, R. J.R., Moffitt, T.E., and Plomin, R. (2005). Evidence for substantial genetic risk for psychopathy in 7-year olds. J. Child. Psychol. Psychiatry 46, 592-597.

Virkkunen, M., Goldman, D., Nielsen, D. A., and Linnoila, M. (1995). Low brain serotonin turnover rate (low CSF 5 HIAA) and impulsive violence. $J$. Psychiatry Neurosci. 20, 271-275.

Vloet, T. D., Herpertz, S., and HerpertzDahlmann, B. (2006). Aetiology and life-course of conduct disorder in childhood: risk factors for the development of an antisocial personality disorder. Z. Kinder Jugendpsychiatr. Psychother. 34, 101-114.

Vloet, T. D., Konrad, K., Huebner, T. Herpertz, S., and Herpertz-Dahlmann, B. (2008). Structured and functional MRI - findings in children and adolescents with antisocial behaviour. Behav. Sci. Law 26, 99-111.
Washburn, J. J., Romero, E. G., Welty, L. J., Abram, K.M., Teplin,L.A., McClelland, G. M., and Paskar, L. D. (2007). Development of antisocial personality disorder in detained youths: the predictive value of mental disorders. J. Consult. Clin. Psychol. 75, 221-231.

Williams, K. M., and Paulhus, D. L. (2004). Factor structure of the Self-Report Psychopathy scale (SRP-II) in nonforensic samples. Pers. Individ. Dif. 37, 765-778.

Wikström, P.-O. H., and Svensson, R. (2008). Why are English youths more violent than Swedish youths?: A comparative study of the role of crime propensity, lifestyles and their interactions in two cities. Eur. J. Criminol. 5, 309-330.

Wilke, M., and Holland, S. K. (2008). Structural MR imaging studies of the brain in children: issues and opportunities. Neuroembryol. Aging 5, 6-13.

Conflict of Interest Statement: The authors declare that the research was conducted in the absence of any commercial or financial relationships that could be construed as a potential conflict of interest.

Received: 31 July 2009; paper pending published: 18 August 2009; accepted: 27 October 2009; published online: 16 November 2009.

Citation: Hodgins S, de Brito S, Simonoff E, Vloet T and Viding E (2009) Getting the phenotypes right: an essential ingredient for understanding aetiological mechanisms underlying persistent violence and developing effective treatments. Front. Behav. Neurosci. 3:44. doi: 10.3389/neuro.08.044.2009

Copyright (c) 2009 Hodgins, de Brito, Simonoff, Vloet and Viding. This is an open-access article subject to an exclusive license agreement between the authors and the Frontiers Research Foundation, which permits unrestricted use, distribution, and reproduction in any medium, provided the original authors and source are credited. 